\title{
COST ANALYSIS OF DISEASE MODIFYING ANTI RHEUMATIC DRUGS: THE INDIAN SCENARIO
}

\begin{tabular}{ll} 
Dr. Zarrin Ansari & Resident, Department of Pharmacology, L.T.M.M.C \& G.H., Mumbai, India. \\
\hline $\begin{array}{l}\text { Dr. Sharmada } \\
\text { Nerlekar }\end{array}$ & $\begin{array}{l}\text { Associate Professor, Department of Pharmacology, L.T.M.M.C \& G.H., } \\
\text { Mumbai, India. }\end{array}$ \\
\hline Dr. Sagar Karia* & $\begin{array}{l}\text { Assistant Professor, Department of Psychiatry, L.T.M.M.C \& G.H., Mumbai, } \\
\text { India. }{ }^{*} \text { Corresponding Author }\end{array}$ \\
\hline Dr. Sudhir Pawar & $\begin{array}{l}\text { Professor and Head, Department of Pharmacology, L.T.M.M.C \& G.H., } \\
\text { Mumbai, India. }\end{array}$ \\
\hline
\end{tabular}

ABSTRACT BACKGROUND: Rheumatoid arthritis is a chronic, autoimmune and inflammatory disease affecting the joints and cartilages, eventually leading towards deformity and resultant disability. Today's rheumatologists have an armamentarium of Disease Modifying Anti Rheumatic Drugs (DMARDs) to choose from. The chronicity of the disease, resultant deformities and reduced work capacity adds to the socioeconomic burden of the disease. This study aims to compare the costs of various brands of DMARDs (both biological and non-biological agents), so as the give the readers an idea about the cost range and variation present amongst the available DMARDs. MATERIALS AND METHODS: Current Index of Medical Specialties (CIMS India) application was accessed in the month of August 2020 to note the cost of various brands of DMARDs. The information was tabulated. The cost difference and percentage cost variation was calculated and compared. RESULTS:The maximum number of brands was available for methotrexate amongst the biological as well as non-biological agents. Least and highest percentage cost variation was observed for $2.5 \mathrm{mg}$ strength of methotrexate and 100 $\mathrm{mg}$ of cyclosporine, respectively. In general, biologicals had fewer brands in the market as the cost was considerably higher than the non-biological agents. CONCLUSION: There is a wide variation amongst the costs of various DMARDs. This has its own advantages. Conscious choice of economical brands can profoundly effect the socioeconomic burden of rheumatoid arthritis management.

\section{KEYWORDS : DMARDs, Rheumatoid Arthritis, Cost Analysis, Percentage Cost Variation, Pharmacoeconomics,} Cost-effectiveness

\section{INTRODUCTION}

Rheumatoid Arthritis (RA) is a chronic, autoimmune and inflammatory disease which affects the skeleton and cartilages, leading to significant disability and decreased quality of life. Swollen, stiff and painful joints are the common symptomatology of RA, eventually leading to deformity of joints and resulting disability [1]. According to a literature search study, the prevalence of RA in the Indian population ranges from $0.28 \%$ to $0.7 \%$ [2].

Rheumatoid arthritis has a profound socio-economic burden. Apart from the cost of medications, functional disability, reduced work capacity and decreased societal participation adds to the socio-economic burden [1]. Early diagnosis and treatment has led to significant reduction of inflammation and consequent damage [3].

The pharmacological management encompasses an armamentarium of disease modifying anti-rheumatic drugs (DMARDs) [1]. With the advent of biological drugs, the pharmacotherapy of RA has been revolutionized, however, at the cost of dramatic increase in the economic burden. The aim of the current study was to evaluate the cost variation of DMARDs amongst different brands in India.

\section{MATERIALS AND METHODS:}

Current Index of Medical Specialties (CIMS India) application, as accessed in the month of August 2020, was used to analyze the prices of DMARDs [4]. The search included both biologicals and non-biological agents. Data regarding the cost across various dosage form and strengths were collected. The cost of tablets was collected per 10 tablets (in one strip).

Differences between minimum and maximum cost were calculated for each agent. Percentage cost variation was calculated for each DMARD using the formula below.
Percentage Price Variation = Price of most expensive brand- Price of least expensive brand

$$
\begin{aligned}
& \text { (PPV) } \\
& \text { ( - }
\end{aligned}
$$$$
\text { Price of least expensive bran }
$$

Biological DMARDs are available only in injectable form and their strengths are not uniform across different brands. Since the strengths of biological agents were not uniform, dosage requirement of each biological DMARD per month was calculated and compared. The formula for Percentage Price Variation for biological DMARDs was as below.

PPV= Maximum Cost per Month-Minimum cost per month X 100

Minimum cost per month

DMARDs having only one manufacturer was also included. Their minimum and maximum cost were calculated as the same and cost difference and variation was noted as zero. As there was no involvement of patients or any intervention, the ethics committee approval was not required for this study.

\section{RESULTS:}

The entire cost-analysis of DMARDs results have been summarized in tables one and two. In general, the number of brands available for a given drug was higher amongst the non-biological drugs versus the biological drugs. Methotrexate had the highest number of brands (thirty-seven) amongst all medications. The lowest number of brands available was for sulfasalazine (six) amongst the nonbiologicals and abatacept (one) amongst the biological DMARDs. The highest number of brands available amongst the biological DMARDs was for rituximab (ten).

Lowest percentage price variation was seen with the lowest strength of methotrexate ( $2.76 \%$ with $2.5 \mathrm{mg}$ of methotrexate). This result excludes drugs with a single brand in the market. Highest percentage price variation was seen with the two strengths of cyclosporine (1387.1\% with $50 \mathrm{mg}$ and $1428.26 \%$ with $100 \mathrm{mg}$ of cyclosporine). Cost analysis of cyclosporine oral solution demonstrated 128.9 percentage price variation. 
Oral solutions were costlier than oral tablets.

As the strengths of biological injectables was not uniform, the results for biological DMARDs was obtained after standardizing the readings to total monthly requirement of the medication. Amongst the biological DMARDs, the lowest percentage price variation was observed with adalimumab injection (13.64\%) and the highest percentage price variation was observed for etanercept (318.04\%).

\section{DISCUSSION:}

In India, the "Drug Price Control Order (DPCO), 2013" is referenced by the National Pharmaceutical Pricing Authority (NPPA) to decide the ceiling price of the available drugs $[5,6]$. Considering the currently increasing healthcare cost and limited healthcare resources, cost analysis is of utmost importance in the setting of chronic diseases including rheumatoid arthritis.

Pharmacoeconomics can be regarded as a branch of health economics which deals with identifying, measuring and comparing the cost of pharmaceutical products and services [7]. Such an analysis helps the physicians to make informed decisions regarding the selection of the most cost-effective management for the patients. Not only the physician but also the patient's preferences must be kept in mind while selecting the desired management, especially in chronic diseases [7].

Our current study focuses upon the cost variation prevailing amongst the different brands of various DMARDs, both biologicals as well as non-biologicals. As commonly known, the difference between the costs of biologicals and nonbiologicals was very large, biologicals being very expensive.
Amongst the expensive biologicals, the highest number of brands available in the market was for rituximab. However, the highest percentage of cost variation was for the TNF alpha inhibitor, etanercept. This can be designated to the price reduction due to the availability of economically priced biosimilars by manufacturers.

Cyclosporine 50 and $100 \mathrm{mg}$ demonstrated the highest percentage cost variation amongst the non-biologicals. Lowest cost was demonstrated for methotrexate $2.5 \mathrm{mg}$ in the entire armamentarium of DMARDs, making it favorable choice as a first-line agent.

National List of Essential Medicine (NLEM) is a list of those medications which satisfy the priority health needs of the population. They are selected after meticulous analysis of the disease incidence, prevalence, efficacy, safety and costeffectiveness. DMARDs viz. methotrexate $(5 \mathrm{mg}, 7.5 \mathrm{mg}$ and 10 $\mathrm{mg})$, azathioprine $(50 \mathrm{mg})$, sulfasalazine $(500 \mathrm{mg})$, leflunomide $(200 \mathrm{mg})$ and hydroxychloroquine (10 $\mathrm{mg}$ and 20 $\mathrm{mg}$ ) are listed under NLEM 2015 [8].

The limitations of this study is that it doesn't estimate the indirect cost in rheumatoid arthritis management. However, this study can help the treating physicians to estimate minimum and maximum cost estimate of drugs for rheumatoid arthritis. Also, it can encourage the physician to prescribe the generic names of drugs in order to reduce the burden of cost of therapy for the ailing patients. Manufacturers can be urged to venture into the making of more biosimilars in the near future. Reduction in the cost of biological DMARDs due to the advent of more biosimilars can potentially revolutionize the treatment scenario of RA in India.

Table 1: Cost-Analysis of various brands of non-biological DMARDs

\begin{tabular}{|c|c|c|c|c|c|c|c|c|}
\hline Drug Name & ATC Code & Total & Dosage Form & $\begin{array}{l}\text { Strength (number of } \\
\text { brands) }\end{array}$ & $\begin{array}{l}\text { Minimum } \\
\text { Cost (INR) }\end{array}$ & $\begin{array}{l}\text { Maximum } \\
\text { Cost (INR) }\end{array}$ & $\begin{array}{l}\text { Cost } \\
\text { difference }\end{array}$ & $\begin{array}{l}\text { Percentage Price } \\
\text { Variation (\%) }\end{array}$ \\
\hline \multirow[t]{4}{*}{ Methotrexate } & L04AX03 & 37 & Tablet & $2.5 \mathrm{mg}(25)$ & 14.91 & 56 & 41.09 & 2.76 \\
\hline & & & & $5 \mathrm{mg}(7)$ & 67 & 89 & 22 & 32.84 \\
\hline & & & & $7.5 \mathrm{mg}(8)$ & 90 & 134 & 44 & 48.89 \\
\hline & & & & $10 \mathrm{mg}(5)$ & 119.65 & 187.5 & 67.85 & 56.71 \\
\hline Azathioprine & L04AX01 & 20 & Tablet & $50 \mathrm{mg}(20)$ & 55.12 & 179.4 & 124.28 & 225.48 \\
\hline \multirow[t]{5}{*}{ Cyclosporine } & L04AD01 & 15 & Capsule & $10 \mathrm{mg}(1)$ & 150 & 150 & 0 & 0 \\
\hline & & & & $25 \mathrm{mg}(11)$ & 221.8 & 2710.6 & 2488.8 & 1122.1 \\
\hline & & & & $50 \mathrm{mg}(11)$ & 337.3 & 5016 & 4678.7 & 1387.1 \\
\hline & & & & $100 \mathrm{mg}(1 \mathrm{l})$ & 639 & 9765.6 & 9126.6 & 1428.26 \\
\hline & & & Oral Solution & $100 \mathrm{mg} \mathrm{x} 1 \mathrm{ml} \times 50 \mathrm{ml}(8)$ & 3050 & 6981.42 & 3931.42 & 128.9 \\
\hline Sulfasalazine & A07EC01 & 6 & Tablet/Capsule & $500 \mathrm{mg}(6)$ & 41.42 & 64.85 & 23.43 & 56.57 \\
\hline \begin{tabular}{|l|} 
Hydroxychlor \\
oquine
\end{tabular} & P01BA02 & 20 & Tablet & $200 \mathrm{mg}(20)$ & 34 & 85 & 51 & 150 \\
\hline \multirow[t]{3}{*}{ Leflunomide } & L04AAl3 & 11 & Tablet & $10 \mathrm{mg}(1 \mathrm{l})$ & 63.52 & 166.67 & 103.15 & 162.39 \\
\hline & & & & $20 \mathrm{mg}(9)$ & 135.15 & 316.1 & 180.95 & 133.89 \\
\hline & & & & $100 \mathrm{mg}(1)$ & 177 & 177 & 0 & 0 \\
\hline
\end{tabular}

Table 2: Cost-Analysis of various brands of biological DMARDs

\begin{tabular}{|c|c|c|c|c|c|c|c|c|}
\hline Drug Name & ATC Code Total brands & Dosage Form & $\begin{array}{c}\text { Approximate } \\
\text { monthly dose }\end{array}$ & $\begin{array}{c}\text { Minimum Cost } \\
\text { per month }\end{array}$ & $\begin{array}{c}\text { Maximum Cost } \\
\text { per month }\end{array}$ & $\begin{array}{c}\text { Cost } \\
\text { Difference }\end{array}$ & $\begin{array}{c}\text { Percentage cost } \\
\text { variation (\%) }\end{array}$ \\
\hline Etanercept & L04AB01 & 4 & Injection & $200 \mathrm{mg}$ & 27500 & 114960 & 87460 & 318.04 \\
\hline Infliximab & L04AB02 & 2 & Injection & $600 \mathrm{mg}$ & 192000 & 246234 & 54234 & 28.25 \\
\hline Adalimumab & L04AB04 & 4 & Injection & $80 \mathrm{mg}$ & 44000 & 50000 & 6000 & 13.64 \\
\hline Abatacept & L04AA24 & 1 & Injection & $1500 \mathrm{mg}$ & 180000 & 180000 & 0 & 0 \\
\hline Rituximab & L01XC02 & 10 & Injection & $2000 \mathrm{mg}$ & 121140 & 320000 & 198860 & 164.16 \\
\hline
\end{tabular}

\section{REFERENCES:}

1. Josef S Smolen, Daniel Aletaha, Iain B McInnes. Rheumatoid arthritis. Lancet 2016; 388: 2023-38.

2. RohiniHanda,U.R.K. Rao,Juliana F. M. Lewis,GautamRambadh,Susan Shiffand Canna J. Ghia. Literature review of rheumatoid arthritis in India. International Journal of Rheumatic Diseases 2016; 19: 440-451

3. Jackie L. Nam. Rheumatoid arthritis management of early disease. Current Opinion in Rheumatology 2016; 28(3): 267-274

4. Current Index of Medical Specialties (CIMS India) application. https://www.mims.com/india. As accessed in the month of August 2020.

5. Drug Price Control Order (DPCO), 2013. http://www.nppaindia.nic.in/wpcontent/uploads/2018/12/DPCO2013 03082016.pdf. As accessed on August
19,2020

6. National Pharmaceutical Pricing Authority (NPPA)

http://www.nppaindia.nic.in/en/dpco/drugs-prices-control- order-2013/ . As accessed on August 19, 2020.

7. Akram Ahmad, Isha Patel, SundararajanParimilakrishnan, Guru Prasad Mohanta, HaeChung Chung, Jongwha Chang. The role of pharmacoeconomics in current Indian healthcare system. J Res Pharm Pract. 2013 Jan-Mar; 2(1): 3-9.

8. Report of the Core-committee for Revision of National List of Essential Medicines. https://cdsco.gov.in/opencms/opencms/en/consumer/EssentialMedicines/As accessed on August 28, 2020 